\title{
The assessment of static balance in children with hearing, visual and intellectual disabilities
}

\author{
Aija Klavina*, Anna Zusa-Rodke, and Zinta Galeja \\ Latvian Academy of Sport Education, Riga, Latvia
}

Copyright: (C) 2017 A. Klavina et al. This is an open access article licensed under the Creative Commons Attribution License (http://creativecommons.org/licenses/by/4.0/).

\begin{abstract}
Background: Balance is a fundamental part of many movement tasks a child performs. Maintaining upright posture is a complex process involving multiple body parts and functional systems. Objective: This study aimed to explore the mean amplitude and velocity of the center of pressure (COP) displacements during static balance tests in children with and without disabilities. Methods: Participants were 34 children (age 8.5 to 10.8 years) including 6 typically developed children, 8 children with hearing, 8 children with visual and 12 children with intellectual disabilities. Static balance data were obtained in $15 \mathrm{~s}$ bipedal stance with eyes open and eyes closed, and also in $10 \mathrm{~s}$ unipedal stance. A force plate was used to collect data of $\mathrm{COP}$ amplitude in anterior-posterior $\left(\mathrm{COP}_{\mathrm{A}-\mathrm{P}}\right)$, medio-lateral $\left(\mathrm{COP}_{\mathrm{M}-\mathrm{L}}\right)$ directions and $\mathrm{COP}$ velocity $\left(\mathrm{COP}_{\mathrm{v}}\right)$. Results: Study outcomes revealed that all subgroups presented larger COP displacement and velocity with eyes closed $(p<.001)$. During bipedal stance with eyes open for results of $\mathrm{COP}_{\mathrm{M} \cdot \mathrm{L}}$ and $\mathrm{COP}_{\mathrm{v}}$ no significant differences were found between children with and without disabilities $(p>.05)$. Children with intellectual and visual impairments presented significantly larger displacement in $\mathrm{COP}_{\mathrm{A}-\mathrm{P}}$ and $\mathrm{COP}_{\mathrm{M}-\mathrm{L}}$ in comparison with children with hearing impairment and without disability $(p<.05)$. Conclusions: This study provided evidence of comparative outcomes on static stability assessment in elementary school children with and without disability. While in many test items children with disability did not demonstrate a significantly decreased level of postural control outcomes comparing to their peers without disability, the balance assessment should be used for early detection of dysfunction in children, so as to guide the application of appropriate intervention.
\end{abstract}

Keywords: static balance, stability, children with disability

\section{Introduction}

Postural control is one of basics for most daily life activities in children. It is the complex ability to maintain, achieve or restore a state of balance while a person is stationary, preparing to move, in motion or preparing to stop moving (De Kegel et al., 2011). Postural control is a complex process based on interaction between visual, vestibular and proprioceptive sensory systems. Reducing the influence of one system leads to postural adaptation due to a compensation by one of the other systems (Legrand et al., 2011). So the complexity is defined as the number of system components and coupling interactions among them (Newell \& Vaillancourt, 2001).

Balance control is a fundamental prerequisite for the motor development of children that typically

\footnotetext{
* Address for correspondence: Aija Klavina, Department of Physiotherapy, Sport Medicine and Adapated Physical Activity, Latvian Academy of Sport Education, Brivibas str. 333, Riga, LV-1006, Latvia. E-mail: aija.klavina@gmail.com
}

is evaluated by using functional tasks with balance constraints, for example, bipedal and/or unipedal stance with eyes open and eyes closed. Furthermore, postural steadiness is often characterized by postural sway estimated from center of pressure (COP) measures obtained from force plate data (Doyle, HsiaoWecksler, Ragan, \& Rosengren, 2007). According to Steindl, Kunz, Schrott-Fischer, and Scholtz (2006) a child reaches postural maturation at about 10 years of age. Postural stability also requires appropriate motor responses to position the center of gravity (COG) within the base of support (Cherng, Lin, Ju, $\&$ Ho, 2009). The motor responses can be coordinated into hip and ankle strategies that maintain anteriorposterior stability in fixed stance (Cherng, Hsu, Chen, $\&$ Chen, 2007). Moreover, postural control is often characterized by postural sway, a kinematic term estimated from COP measures derived from force plate data (De Kegel et al., 2011; Doyle et al., 2007; Lin, Seol, Nussbaum, \& Madigan, 2008). Reported findings 
of postural stability abnormalities in children with disabilities may be biased by the influence of moderating variables, such as age, severity of impairment, daily physical activity level and other. For example, according previous studies hearing impaired children with intact balance function and no other health problems can present motor and vestibular development similar to typically developing children (De Kegel et al., 2011). However, other studies reported that children with hearing impairment had a high incidence of vestibular deficit (del Pino, Femia, \& Perez-Fernandez, 2011; Gheysen, Loots, \& Van Waelvelde, 2008). However, the postural disturbances might be corrected by the time these children grow older. Therefore, it is important to examine the severity of the balance disturbances that indicates the maturity level of posture control in these children (An, Yi, Jeon, \& Park, 2009). Regarding children with intellectual disabilities many authors have explored postural control and physical activity parameters related to the type of intellectual impairment, for example, autism spectrum disorders (Minshew, Sung, Jones, \& Furman, 2004; Philips \& Holland, 2011). However, limited studies have been done on posture assessment in a heterogynous group including children with different intellectual disability. Also, researchers have found that when balance tasks are simple, for example, standing on two feet with eyes open on a firm surface, there is little difference between individuals with and without disability, while increase of task difficulty (e.g., standing with eyes closed) also tend to increase postural instability when compared with typically developing peers (Graham et al., 2015; Stins, Emck, de Vries, Doop, \& Beek, 2015). Several studies of postural control in children with visual impairment (VI) found that degree of vision loss presented insufficient relationship with the ability to maintain static balance (Houwen, Visscher, Lemmink, \& Hartman, 2008; Juodžbalienè \& Muckus, 2006). The authors have concluded that the poor performance of children with VI is related to vision, but the degree of the VI does not appear to relate to motor performance.

Long-term studies have reported declines in balance performance in children over the past 25-35 years (Jurimae, Volbekiene, Jurimae, \& Tomkinson,
2007). Balance is a fundamental skill for the motor development and physical activity (PA) performance of children. The dynamic and complex nature of daily $\mathrm{PA}$ requires measurement selection practices to concurrently evolve in order to adequately capture PA behaviors in children with different physical potential. However, the current focus on movement outcomes in children with sensory, physical or intellectual impairments have been aligned with biomedical or disability related concept. Therefore, it may be appropriate to capture and describe the unique behavior patterns of children with various abilities according their nuanced performance of PA (Kang, Palisano, King, \& Chiarello, 2014). Knowledge about balance and muscle strength status may thus be important for both, the identification of children with an increased fall and injury risk and the development of appropriate PA intervention programs.

This study aimed to investigate the range and velocity of COP displacements during static balance tests in elementary school age children with and without disabilities.

\section{Methods}

\section{Participants}

The observed group consisted of 34 children with and without disabilities divided in 4 subgroups, (1) control group (CG) - 6 healthy typically developing children with no history of any pathology, (2) 8 children with hearing impairments (HI), (3) 8 children with visual impairments (VI), and (4) 12 children with intellectual disabilities (ID). Age, height and weight in all observed groups are presented in Table 1. All children with disabilities were previously diagnosed by medical doctors (e.g., neurologist, pediatrician, psychiatrist) recommending them special education programs classified by specific codes. Thus, all children with disabilities attended special education classes with codes indicating mild and moderate disability. For example, children with HI were selected from classes with code 52 that defines special education program for children with hearing disability. Children with ID were selected from classes with code 57 and 58 that defines special

Table 1

Mean age, height and weight of participants

\begin{tabular}{lcccc}
\hline & CG group $(n=6)$ & HI group $(n=8)$ & VI group $(n=8)$ & ID group $(n=12)$ \\
\hline Age (years) & $8.5 \pm 1.0$ & $10.8 \pm 0.7$ & $9.6 \pm 1.1$ & $8.6 \pm 1.2$ \\
Height $(\mathrm{cm})$ & $140.5 \pm 6.8$ & $147.8 \pm 13.8$ & $138.5 \pm 4.8$ & $134.1 \pm 6.9$ \\
Weight $(\mathrm{kg})$ & $30.4 \pm 5.3$ & $34.6 \pm 8.8$ & $30.5 \pm 4.9$ & $27.7 \pm 5.0$ \\
\hline
\end{tabular}

Note. $\mathrm{CG}=$ typically developing group; $\mathrm{HI}=$ hearing impaired group; $\mathrm{VI}=$ visual impaired group; $\mathrm{ID}=$ intellectual disabled group. 
education programs for children with mild and moderate intellectual disability. Children with VI were selected from classes with code 51 that defines special education program for children with visual impairment (Cabinet of Ministers of Latvia, 2008). In this subgroup all children were the partially sighted having moderate or severe VI (category 1,2) visual acuity of less than 6/18 and not better than 3/60 (ICD-10; World Health Organization, 2012). Additional inclusion criteria were the ability to perform independent standing and walking abilities, and understanding instructions with or without assistance (e.g., special education teacher/interpreter explained instruction in sign language for children with $\mathrm{HI}$ ). All children could use their technical aids (e.g., hearing aids) during the study. The exclusion criteria were orthopedic problems and severe or/and profound intellectual disability. The group of 6 age and gender matched peers with no impairments were recruited for the control subgroup. The study received the Ethics Committee approval of the affiliated institution of the authors of this study. All participants and/or their parents/guardians provided written consent prior to the study.

\section{Assessment of postural control}

Postural measurements were conducted for all participants with two force plates (BTS P-6000, $60 \times 40 \mathrm{~cm}$, BTS, Garbagnate Milanese, Italy). Data were sampled out at $200 \mathrm{~Hz}$ and the plates were calibrated before each test. For each test condition the mean amplitude of anterior-posterior (AP) and of medio-lateral (ML) displacement of the COP was calculated using the Sway software (BTS, Garbagnate Milanese, Italy). Ground reaction forces collected from the force plates were processed and the location of the COP was determined. Also, the affiliated outcome was the velocity of $\mathrm{COP}$ displacement $\left(\mathrm{COP}_{\mathrm{v}}\right.$ in $\left.\mathrm{cm} / \mathrm{s}\right)$.

\section{Procedures}

The postural control measures were conducted at the kinesiology lab of the affiliated institution. Each child performed $15 \mathrm{~s}$ bipedal stance in two conditions - eyes open (EO) and eyes closed (EC) and $10 \mathrm{~s}$ unipedal stance on one leg on the force plate. All participants completed 3 test sessions consisting of one training and two control trials with $1 \mathrm{~min}$ resting intervals between sessions. All participants were barefoot and instructed to stand as still as possible with feet, arms and eyes contact points strictly defined in two assessment conditions, (1) during bipedal stance - feet together, arms free on sides, and (2) during unipedal stance - hands placed on hips, while eyes contact point in both conditions was $3.5 \mathrm{~m}$ away straight forward.

\section{Data analysis}

Data analyses were performed with IBM SPSS Statistics (Version 19.0; IBM, Armonk, NY, USA). Descriptive statistics were used for data obtained from the COP results. The Kolmogorov-Smirnov test was used to determine the normality of distribution. Kruskal-Wallis procedures were applied to determine if differences existed among COP data across the four subgroups. The Mann-Whitney $U$ post-hoc tests were used to determine differences by subgroups. COP amplitude in anteriorposterior, medio-lateral directions and sway velocity were main used postural control outcomes. In addition, the differences in results were analyzed for COP displacement between A-P and M-L directions for the study sample. Statistical significance level was set at 05 .

\section{Results}

In assessing the COP displacement outcomes between the four subgroups, results presented significant differences during bipedal stance with eyes open for $\mathrm{COP}_{\text {A.P }}(p=.049)$, during unilateral stance on left leg for $\mathrm{COP}_{\mathrm{M}-\mathrm{L}}(p=.013)$, and for $\mathrm{COP}_{\mathrm{V}}(p=.044)$, and during unilateral stance on right leg for $\mathrm{COP}_{\mathrm{A}-\mathrm{P}}(p=.018)$, $\mathrm{COP}_{\mathrm{M}-\mathrm{L}}(p=.046)$, and for $\mathrm{COP}_{\mathrm{V}}(p=.005)$.

Table 2 presents the mean and standard deviation of the COP displacement in A-P and M-L directions, and velocity of sway. The COP displacement was significantly larger in children with ID in comparison with VI in A-P directions $(p=.047)$. Furthermore, children with ID displayed significantly larger COP displacement in A-P directions and M-L directions in comparison with $\mathrm{HI}$ during unipedal stance on the left leg $(p=.010$ and $p=.003$, respectively). Children with VI performed significantly faster COP displacements than HI $(p=.038)$. During unipedal stance on the right leg children with VI displayed significantly larger COP displacement in both directions (A-P, M-L) and COP velocity than children with HI ( $p=.017)$. Also, children with VI had significantly larger COP displacement in A-P directions and velocity than CG children $(p=.014$ and $p=.035$, respectively). Interesting results were found in CG compared to HI group indicating that typically developing children performed larger COP sway than their peers with $\mathrm{HI}$ while standing on the right leg $\left(p_{\mathrm{A}-\mathrm{P}}=.050\right.$ and $\left.p_{\mathrm{M}-\mathrm{L}}=.035\right)$. The additional analyses of COP displacement for the research sample revealed significantly increased of COP oscillation in M-L directions in both conditions, with EO and EC $(p<.001)$. Also, there were significant differences across the three test variables in two conditions, eyes closed and eyes open. All subgroups presented larger COP displacement and velocity with eyes closed $(p<.001)$. 
Table 2

Mean and standard deviation of the COP results obtained for all participants

\begin{tabular}{|c|c|c|c|c|}
\hline & CG group & HI group & VI group & ID group \\
\hline \multicolumn{5}{|l|}{ Bipedal stance EO } \\
\hline $\mathrm{COP}_{\mathrm{A}-\mathrm{P}}$ amplitude $(\mathrm{mm})$ & $1.9 \pm 1.0$ & $2.2 \pm 1.1$ & $2.6 \pm 3.2^{\mathrm{d}}$ & $3.2 \pm 1.6^{\mathrm{c}}$ \\
\hline $\mathrm{COP}_{\mathrm{M}-\mathrm{L}}$ amplitude $(\mathrm{mm})$ & $2.2 \pm 1.0$ & $3.2 \pm 2.7$ & $4.0 \pm 2.1$ & $3.2 \pm 1.7$ \\
\hline COP velocity $\left(\mathrm{cm} / \mathrm{s}^{2}\right)$ & $1.4 \pm 0.4$ & $1.4 \pm 0.4$ & $2.2 \pm 1.1$ & $1.8 \pm 0.5$ \\
\hline \multicolumn{5}{|l|}{ Bipedal stance EC } \\
\hline $\mathrm{COP}_{\mathrm{A} \cdot \mathrm{P}}$ amplitude $(\mathrm{mm})$ & $3.1 \pm 1.2$ & $2.5 \pm 0.8$ & $4.3 \pm 4.5$ & $3.9 \pm 2.4$ \\
\hline $\mathrm{COP}_{\mathrm{M}-\mathrm{L}}$ amplitude $(\mathrm{mm})$ & $2.9 \pm 1.4$ & $2.8 \pm 1.9$ & $3.4 \pm 1.8$ & $3.8 \pm 0.9$ \\
\hline COP velocity $(\mathrm{cm} / \mathrm{s})$ & $2.1 \pm 0.5$ & $2.0 \pm 0.7$ & $2.5 \pm 1.2$ & $2.7 \pm 0.8$ \\
\hline \multicolumn{5}{|l|}{ Unipedal stance on left leg } \\
\hline $\mathrm{COP}_{\mathrm{A} \cdot \mathrm{P}}$ amplitude (mm) & $3.9 \pm 2.6$ & $3.0 \pm 0.6^{\mathrm{d}}$ & $3.9 \pm 1.4$ & $5.1 \pm 4.4^{\mathrm{b}}$ \\
\hline $\mathrm{COP}_{\mathrm{M}-\mathrm{L}}$ amplitude $(\mathrm{mm})$ & $5.5 \pm 3.6$ & $3.3 \pm 0.9^{\mathrm{d}}$ & $7.3 \pm 4.7$ & $7.7 \pm 5.1^{b}$ \\
\hline COP velocity $(\mathrm{cm} / \mathrm{s})$ & $5.6 \pm 1.6$ & $3.9 \pm 0.8^{c}$ & $7.2 \pm 2.7^{\mathrm{b}}$ & $8.1 \pm 5.9$ \\
\hline \multicolumn{5}{|l|}{ Unipedal stance on right leg } \\
\hline $\mathrm{COP}_{\mathrm{A}-\mathrm{P}}$ amplitude $(\mathrm{mm})$ & $3.9 \pm 2.5^{b, c}$ & $3.0 \pm 0.6^{\mathrm{c}}$ & $9.6 \pm 4.8^{\mathrm{a}, \mathrm{b}}$ & $4.3 \pm 4.0$ \\
\hline $\mathrm{COP}_{\mathrm{M} \cdot \mathrm{L}}$ amplitude $(\mathrm{mm})$ & $5.9 \pm 4.3^{\mathrm{b}}$ & $3.2 \pm 0.8^{\mathrm{a}, \mathrm{c}}$ & $11.0 \pm 6.0^{\mathrm{b}}$ & $5.6 \pm 3.8$ \\
\hline COP velocity $(\mathrm{cm} / \mathrm{s})$ & $5.7 \pm 2.8^{\mathrm{c}}$ & $3.8 \pm 0.8^{\mathrm{c}}$ & $13.2 \pm 8.6^{\mathrm{a}, \mathrm{b}}$ & $6.1 \pm 2.3$ \\
\hline
\end{tabular}

Note. $\mathrm{CG}=$ typically developing group; $\mathrm{HI}=$ hearing impaired group; $\mathrm{VI}=$ visual impaired group; $\mathrm{ID}=$ intellectual disabled group. $\mathrm{EO}=$ eyes open; $\mathrm{EC}=$ eyes closed; A-P = anterior-posterior direction; $\mathrm{M}-\mathrm{L}=$ medio-lateral direction. Significantly different $(p<.05)$ from the respective value: ${ }^{\mathrm{a}} \mathrm{CG}$ group; ${ }^{\mathrm{b}} \mathrm{HI}$ group; ${ }^{\mathrm{C}} \mathrm{VI}$ group; and ${ }^{\mathrm{d}} \mathrm{ID}$ group.

\section{Discussion}

We did not find comparative studies on postural control assessment of elementary school children with different disabilities and typically developed peers. The results of this study revealed that, in general, children with mild and moderate disability did not demonstrate significantly decreased levels of postural control outcomes comparing to their peers without disability. In several conditions during bipedal stance (for example, with eyes closed for all results, with eyes open for results of $\mathrm{COP}_{\mathrm{M}-\mathrm{L}}$ and $\mathrm{COP}_{\mathrm{V}}$ ), there was no significant difference in results between children with and without disabilities. Regarding children with HI our results were partially in line with study outcomes of Suarez et al. (2007) indicating that children with HI had similar outcomes with control group on postural test in standing position on a force platform with eyes open. The possible confounding variable could be the age of participants. While there were no significant age differences across the four groups, the mean age of HI children was slightly higher than for other subgroups (Table 1). Previous research studies indicate that children between 7 to 8 years begin to present similarities of gait and balance to adults (Cuisinier, Olivier, Vaugoyeau, Nougier, \& Assaiante, 2011; Kirshenbaum, Riach, \& Starkes, 2001). Thus, the mean age of HI children, which is an important factor in their balance ability, could be related to their mature balance skills. However, other authors have reported larger COP scores for children with HI than for control groups (de Sousa, Barros, \& de Sousa Neto, 2012; Gheysen et al., 2008).

Several studies suggested that COP is affected in children with VI because of the loss of sensory information (Brambring, 2007; Ray \& Wolf, 2010). Moreover, in our study there was large variability in the results on the right leg for children with VI comparing to the left leg. These outcomes were in line with previous study by Klavina and Jekabsone (2014) indicating that young adults with VI could not keep the balance for the required period of time (10 seconds) when standing on the right leg. To explain these findings, two studies have supported the concept that humans are typically right dominant for movements requiring locomotion and object manipulation while they are left dominant for maintaining postural stability (Uysal, 2011; Elisa et al., 2002). Furthermore, previous studies have suggested that unilateral balance tasks might depend on some neuromuscular requirement (Hazime et al., 2012) and muscular strength (Giagazoglou et al., 2009; Shumway-Cook \& Woollacott, 2001). The ability of the body balance system to select a higher joint configuration variance (Hsu, Scholz, Schoner, Jeka, \& Kiemel, 2007; Krishnamoorthy, Yang, \& Scholz, 2005) can contribute to the maintenance of postural stability by correcting lower extremity movements in 
individuals with vision impairments. However, this biomechanical balance strategy cannot be generalized to other groups of young children. Previous study by Roncesvalles, Woollacott, and Jensen (2001) tested the hypothesis that improvement of children's balance control during development could be described from examining changes in kinetic response characteristics associated with maturation of postural control. Furthermore, Alexandrov, Frolov, Horak, Carlson-Kuhta, and Park (2005) in their study demonstrated that children at 6-10 years of age utilize variability in multiple segments to facilitate the center of mass control in quiet stance. They indicated that while the ankle, knee, and hip joints are the major joints providing postural stability, this multi-joint pendulum system lacks the capability of revealing how its variability is allocated and utilized to maintain a stable posture.

In previous studies persons with ID have demonstrated more restricted postural control outcomes, including static balance, than control groups (Blomqvist, Olsson, Wallin, Wester, \& Rehn, 2013). Several authors indicated that these children have poor postural adjustment abilities compared with typically developing peers (Chen, Yeh, \& Howe, 2015; Wang, Long, \& Liu, 2012). Our results were opposite presenting, in general, no or few difference in outcomes of the static balance between children with and without ID. This might be explained by selection criteria in this study where participants with ID did not have profound intellectual impairment and/or severe autism spectrum disorder, or Down syndrome. Furthermore, study by Cheldavi, Shakerian, Boshehri, and Zarghami (2014) have presented that special balance training can improve postural control outcomes while using different sensory conditions in ID children. Participants in our study were selected from special education settings where physical education was provided two times per week (40 min each) and additional after school activities were available at the education setting that might contribute balance (e.g., dancing, therapeutic recreation, and swimming). Some authors have noted that even difference in postural control did not present in childhood comparing children with and without ID, the gap increased by age (Blomqvist et al., 2013; Lahtinen, Rintala, \& Malin, 2007).

All subgroups, presented slightly larger body sway with EC condition (Table 2). This is similar to what is observed in typically developing children. These findings extend prior observations showing that children, also those with disabilities, are more dependent on visual stimuli (Shumway-Cook \& Woollacott, 2001). Vision provides external information to the body, based on visual cues in the environment. These cues may help compensate for insufficient function in the somatosensory or vestibular systems, while limited or lack of visual cues affects ability to maintain the body position (Horak \& Macpherson, 1996).

\section{Conclusions}

The study results revealed that children with and without disability exhibited better static balance parameters with eyes open compared to eyes closed condition. The COP displacement for children with ID was significantly larger than for children with VI, HI and control group. While children in the CG in general presented superior static balance parameter values than did their peers with disability, in some test conditions children with HI had significantly better results. Our study highlighted the importance of identifying postural stability measures in children with and without disabilities in young age.

\section{Acknowledgments}

This study was supported by the EEA/Norway Grants "Research and Scholarship" program in Latvia and done within the project "Health and Social Indicators of Participation in Physical Activities for Children with Disabilities" (NFI/R/2014/070).

\section{Conflict of interest}

There were no conflicts of interest.

\section{References}

Alexandrov, A. V., Frolov, A. A., Horak, F. B., Carlson-Kuhta, P., \& Park, S. (2005). Feedback equilibrium control during human standing. Biological Cybernetics, 93, 309-322.

An, M. H., Yi, C. H., Jeon, H. S., \& Park, M. H. (2009). Agerelated changes of single-limb standing balance in children with and without deafness. International Journal of Pediatric Otorhinolaryngology, 73, 1539-1544.

Blomqvist, S., Olsson, J., Wallin, L., Wester, A., \& Rehn, B. (2013). Adolescents with intellectual disability have reduced postural balance and muscle performance in trunk and lower limbs compared to peers without intellectual disability. Research in Developmental Disabilities, 34, 198-206.

Brambring, M. (2007). Divergent development of manual skills in children or sighted. Journal of Visual Impairment and Blindness, 101, 212-215.

Cabinet of Ministers of Latvia. (2008). Noteikumi par Latvijas izglìtîbas klasifikāciju [Regulation on classification of special education]. Cabinet of Ministers of Latvia, 
regulation nr. 990. Retrieved from https://likumi.lv/doc. php?id=184810

Cheldavi, H., Shakerian, S., Boshehri, S. N. S., \& Zarghami, M. (2014). The effects of balance training intervention on postural control of children with autism spectrum disorder: Role of sensory information. Research in Autism Spectrum Disorders, 8, 8-14.

Chen, H. L., Yeh, C. F., \& Howe, T. H. (2015). Postural control during standing in children with Down syndrome. Research in Developmental Disabilities, 38, 345-351.

Cherng, R. J., Hsu, Y. W., Chen, Y. J., \& Chen, J. Y. (2007). Standing balance of children with developmental coordination disorder under altered sensory conditions. Human Movement Science, 26, 913-926.

Cherng, R. J., Lin, H. C., Ju, Y. H., \& Ho, C. S. (2009). Effect of seat surface inclination on postural stability and forward reaching efficiency in children with spastic cerebral palsy. Research in Developmental Disabilities, 30, 1420-1427.

Cuisinier, R., Olivier, I., Vaugoyeau, M., Nougier, V., \& Assaiante, C. (2011). Reweighting of sensory inputs to control quiet standing in children from 7 to 11 and in adults. PLOS ONE, 6(5), e19697.

De Kegel, A. D., Dhooge, I., Cambier, D., Baetens, T., Palmans, T., \& Waelvelde, H. V. (2011). Test-retest reliability of the assessment of postural stability in typically developing children and in hearing impaired children. Gait \& Posture, 33, 679-685.

de Sousa, A. M. M., Barros, J. F., \& de Sousa Neto, B. M. (2012). Postural control in children with typical development and children with profound hearing loss. International Journal of General Medicine, 5, 433-439.

del Pino, G., Femia, P., \& Perez-Fernandez, N. (2011). Vestibular examination of children with alteration in balance (II): Results by pathologies. Acta Otorhinolaryngology Espania, 62, 385-391.

Doyle, R. J., Hsiao-Wecksler, E. T., Ragan, B. G., \& Rosengren, K. S. (2007). Generalizability of center of pressure measures of quiet standing. Gait \& Posture, 25, 166-171.

Elisa, F., Josee, L., Oreste, F. G., Claudia, A., Antonella, L., \& Sabrina, S. (2002). Gross motor development and reach on sound as critical tools for the development of the blind child. Brain Development, 24, 269-275.

Gheysen, F., Loots, G., \& Van Waelvelde, H. (2008). Motor development of deaf children with and without cochlear implants. Journal of Deaf Studies and Deaf Education, 13, 215-224.

Giagazoglou, P., Amiridis, I. G., Zafeiridis, A., Thimara, M., Kouvelioti, V., \& Kellis, E. (2009). Static balance control and lower limb strength in blind and sighted women. European Journal of Applied Physiology, 107, 571-579.

Graham, S. A., Abbott, A. E., Nair, A., Lincoln, A. J., Muller, R. A., \& Goble, D. J. (2015). The influence of task difficulty and participant age on balance control in ASD. Journal of Autism and Developmental Disorders, 45, 1419-1427.

Hazime, F. A., Allard, P., Ide, M. R., Siqueira, C. M., Amorim, C. F., \& Tanaka, C. (2012). Postural control under visual and proprioceptive perturbations during double and single limb stance. Journal of Body Movement and Therapy, 16, 224-229.
Horak, F., \& Macpherson, J. M. (1996). Postural orientation and equilibrium. In Handbook of physiology (pp. 255-292). New York, NY: American Physiological Society.

Houwen, S., Visscher, C., Lemmink, K. A. P. M., \& Hartman, E. (2008). Motor skill performance of school-age children with visual impairments. Developmental Medicine in Child Neurology, 50, 139-145.

Hsu, W. L., Scholz, J. P., Schoner, G., Jeka, J. J., \& Kiemel, T. (2007). Control and estimation of posture during quiet stance depends on multijoint coordination. Journal of Neurophysiology, 97, 3024-3035.

Juodžbaliene, V., \& Muckus, K. (2006). The influence of degree of visual impairment on psychomotor reaction and equilibrium maintenance of adolescents. Medicina (Kaunas), 42, 49-56.

Jurimae, T., Volbekiene, V., Jurimae, J., \& Tomkinson, G. R. (2007). Changes in Eurofit test performance of Estonian and Lithuanian children and adolescents (1992-2002). Medicine and Sport Science, 50, 129-142.

Kang, L.-J., Palisano, R. J., King, G. A., \& Chiarello, L. A. (2014). A multidimensional model of optimal participation of children with physical disabilities. Disability and Rehabilitation, 36, 1735-1741.

Kirshenbaum, N., Riach, C. L., \& Starkes, J. L. (2001). Nonlinear development of postural control and strategy use in young children: A longitudinal study. Experimental Brain Research, 140, 420-431.

Klavina, A., \& Jekabsone, I. (2014). Static balance of persons with intellectual disabilities, visual impairment and without disabilities. European Journal in Adapted Physical Activity, 7(1), 50-57.

Krishnamoorthy, V., Yang, J. F., \& Scholz, J. P. (2005). Joint coordination during quiet stance: Effects of vision. Experimental of Brain Research, 164, 1-17.

Lahtinen, U., Rintala, P., \& Malin, A. (2007). Physical performance of individuals with intellectual disability: A 30 years follow up. Adapted Physical Activity Quarterly, 24, 125-143.

Legrand, A., Quoc, E. B., Vacher, S. W., Ribot, J., Lebas, N., Milleret, C., \& Bucci, M. P. (2011). Postural control in children with strabismus: Effect of eye surgery. Neuroscience Letters, 501, 96-101.

Lin, D., Seol, H., Nussbaum, M. A., \& Madigan, M. I. (2008). Reliability of COP-based postural sway measures and agerated differences. Gait \& Posture, 28, 337-342.

Minshew, N. J., Sung, K., Jones, B. L., \& Furman, J. M. (2004). Underdevelopment of the postural control system in autism. Neurology, 63, 2056-2061.

Newell, K. M., \& Vaillancourt, D. E. (2001). Dimensional change in motor learning. Human Movement Science, 20, 695-715.

Philips, A. C., \& Holland, A. (2011). Assessment if objectively measured physical activity levels in individuals with intellectual disabilities with and without Down's syndrome. PLOS ONE, 6(12), e28618.

Ray, C. T., \& Wolf, S. L. (2010). Gender differences and the risk of falls in individuals with profound vision loss. Journal of Visual Impairment and Blindness, 104, 311-316.

Roncesvalles, N., Woollacott, M., \& Jensen, J. (2001). Development of lower extremity kinetics for balance control in 
infants and young children. Journal of Motor Behavior, 33, 180-192.

Shumway-Cook, A., \& Woollacott, M. H. (2001). Motor control: Theory and practical applications. Baltimore, MD: Lippincott Williams and Wilkins.

Steindl, R., Kunz, K., Schrott-Fischer, A., \& Scholtz, A. W. (2006). Effect of age and sex on maturation of sensory systems and balance control. Developmental Medicine of Child Neurology, 48, 477-482.

Stins, J. F., Emck, C., de Vries, E. M., Doop, S., \& Beek, P. J. (2015). Attentional and sensory contributions to postural sway in children with autism spectrum disorder. Gait \& Posture, 42, 199-203.
Suarez, H., Angeli, S., Suarez, A., Rosales, B., Carrera, X., \& Alonso, R. (2007). Balance sensory organization in children with profound hearing loss and cochlear implants. International Journal of Pediatric Otorhinolaryngology, 71, 629-637.

Uysal, S. A. (2011). A comparison of motor skills in Turkish children with different visual acuity. Fizyoterapy Rehabilitasyon, 22, 23-29.

Wang, H. Y., Long, I. M., \& Liu, M. F. (2012). Relationship between task-oriented postural control and motor ability in children and adolescents with Down syndrome. Research in Developmental Disabilities, 33, 1792-1798.

World Health Organization. (2012). CD-10 Version: 2010. Retrieved from http://apps.who.int/classifications/icd10/ browse/2010/en\#/H54 